\title{
ESTUDO DE ESTABILIDADE SOB ARMAZENAMENTO DA CARNE DE EMA (Rhea americana) ${ }^{1}$
}

\author{
Amanda V. PEREIRA², Pedro F. ROMANELLI², Andréia B. SCRIBONI², Sílvia R. BARBOZA²
}

\section{RESUMO}

Utilizou-se o músculo Iliotibialis lateralis da sobrecoxa da ema (Rhea americana) para a realização das análises de estabilidade da carne sob armazenamento em refrigeração e congelamento. Na avaliação da carga microbiológica da carne foram realizadas análises de Coliformes Totais, Coliformes Fecais (Escherichia coli) e psicrotróficos. No período de zero a 12 dias de refrigeração determinou-se o pH da carne e a degradação protéica através da análise de Nitrogênio Volátil Total (NVT). Durante o congelamento (período de 60 dias) avaliou-se o pH e a oxidação lipídica pela análise do número de TBA da carne armazenada. As amostras sob refrigeração e congelamento mostraram-se adequadas ao consumo, não apresentando contaminação microbiológica durante todo o período de estocagem. Os valores de Nitrogênio Volátil Total (NVT) da carne sob refrigeração tiveram uma evolução insignificante (4\%) entre o tempo zero e o $12^{\circ}$ dia de estocagem. Durante o congelamento ocorreu um aumento significativo do número de TBA nas amostras, com variações de 1,5-2,5 mg de SRATB/1.000 g amostra. Os valores de pH da carne de ema armazenada sob refrigeração e congelamento mantiveram-se praticamente estáveis em torno de 5,8 .

Palavras-chave: degradação protéica, oxidação lipídica, vida de prateleira, refrigeração, congelamento.

\section{SUMMARY}

STUDY OF THE GREAT RHEA (Rhea americana) MEAT STABILITY UNDER STORAGE. The Great Rhea (Rhea americana) thigh muscle Iliotibialis lateralis was used to perform analyses of the meat stability under refrigeration and freezing storage. Analyses on fecal (Escherichia coli), total coliforms and psycrotrophic organisms were performed for the evaluation of the microbiological load at the meat. The meat $\mathrm{pH}$ and protein degradation have been determined by Total Volatile Basic Nitrogen (TVBN) analyses from time zero to the $12^{\text {th }}$ day of refrigeration. During the freezing period (60 days), the $\mathrm{pH}$ and lipidic oxidation have evaluated through the analyses of TBARs number in the stored meat. The samples under refrigeration and freezing were adequate to consumption and they not presented microbiological contamination during all storage period. The Total Volatile Basic Nitrogen (TVBN) of the meat under refrigeration presented an insignificant evolution (4\%) between time zero and the $12^{\text {th }}$ day of storage. A significant increase of TBARs number of the sample occurred during the freezing, ranging from 1.5-2.5mg of TBARs/1000 g of the sample. The pH values of the stored meat under refrigeration and freezing remained practically stable, showing values around 5.8.

Keywords: protein degradation, lipidic oxidation, shelf life, refrigeration, freezing.

\section{1 - INTRODUÇÃO}

Nos últimos anos tem crescido muito o interesse pela criação de ratitas, como emas e avestruzes. Na realidade, pode ser o surgimento de uma nova indústria. As granjas de criação comercial destas aves estão despertando o interesse de novos criadores e se tornando uma grande alternativa zootécnica [6].

Em passado ainda recente, o mercado mais favorável dessas espécies era o comércio de reprodutores, o que inibiu de certa forma o desenvolvimento dos mercados de carne, óleo e couro obtidos com o abate destas aves. No entanto, a indústria atingiu um patamar tal que, o aumento na disponibilidade de aves resultou em um concomitante decréscimo no preço individual destes animais, criando assim um mercado para o abate, necessário para o desenvolvimento da indústria [6].

\footnotetext{
${ }^{1}$ Recebido para publicação em 3/12/2004. Aceito para publicação em 28/04/2006 (001448)

${ }^{2}$ Departamento Engenharia e Tecnologia de Alimentos da Unesp, Campus de São José do Rio Preto

Rua Cristóvão Colombo, 2.265, Jardim Nazareth

CEP 15054-000 - São José do Rio Preto (SP)

E-mail:pereiramanda@terra.com.br,romaneli@eta.ibilce.unesp.br *A quem a correspondência deve ser enviada
}

Atualmente, os principais produtos da indústria da ema são a carne, o couro e as plumas. Em muitos lugares, a criação comercial de ema está concentrada na produção de carne, direcionada para um mercado consciente sobre qualidade e saúde, principalmente na Europa, após o surgimento da "doença da vaca louca” (Encefalite Espongiforme Bovina-BSE). Um outro aspecto a ser destacado sobre a carne de ratitas é que, ao contrário da carne bovina, ela está livre de parasitas que possam ser transmitidos para o consumidor [15].

Pelo seu perfil quantitativo de lipídios, a carne de ema (Pterocnemia pennata) apresenta valor calórico menor do que as carnes bovina, de frango e suína. Tendo em vista, sua cor vermelha característica, elevado teor protéico e uma boa aceitação pelo consumidor, a carne de ema tende a ser uma nova opção de consumo [18].

O baixo conteúdo de gordura intramuscular, na carne de ema e avestruz, é uma grande vantagem para divulgação como um produto saudável, em relação às doenças cardíacas que são consideradas um grande problema de saúde pública [29].

O tempo de vida de prateleira é um atributo importante de todos os alimentos. Pode ser definido como o tempo que se passa desde a produção, embalagem até o ponto em que o alimento se torna inaceitável para o consumo [13]. 
No entanto, são limitadas as informações que avaliam a vida de prateleira da carne de ema ou avestruz. Para competir no mercado de produtos cárneos frescos, é importante que sejam determinadas as características de shelf life sensorial e microbiológica dessa carne [23].

Portanto, este trabalho teve o propósito de avaliar a estabilidade da carne de ema armazenada sob refrigeração e congelamento.

\section{2 - MATERIAL E MÉTODOS}

Foram utilizados 11 animais de ambos os sexos da espécie Rhea americana. As aves foram submetidas a um sistema de confinamento dos 6 aos 12 meses de idade, recebendo ração comercial balanceada à vontade (Nutriavestruz ${ }^{\circledR}$ Crescimento da Purina: $18 \% \mathrm{~PB}, 3,50 \% \mathrm{EE}$ ), e com acesso a um piquete composto por três tipos de forrageiras: Panicum maximum Jacq. Var. Trichoglume cv. Petrie (green panic) maior população presente, Digitaria horizontalis Willd. (capim colchão) e Eleusine indica (L.) Gaertn (capim pé-de-galinha).

Para o abate, as 11 emas com 12 meses de idade, previamente identificadas com brincos numerados, foram divididas aleatoriamente em quatro lotes: um com duas aves e os outros com três. O abate foi realizado no período de um mês, sendo que a cada semana foi abatido um lote de emas. Os abates foram realizados nas dependências do laboratório de carne e derivados com instalações adaptadas.

Antes do abate as aves foram submetidas a um jejum hídrico de $12 \mathrm{~h}$, pesadas e em seguida processadas conforme os procedimentos normais de abate: atordoamento elétrico, sangria, depenagem manual, esfola e evisceração.

As amostras de carne foram compostas pela mistura dos músculos Iliotibialis lateralis (situado na sobrecoxa) de todas as emas de cada lote, ou seja, cada amostra correspondeu a um lote de abate. Para todas as etapas do trabalho, as amostras (carne in natura) foram trituradas e homogeneizadas, separadas em sacos plásticos devidamente etiquetados e armazenadas sob refrigeração ou congelamento para os estudos posteriores de acordo com a metodologia a ser seguida.

O acompanhamento da estabilidade da carne sob refrigeração foi realizado através da medida de pH [10] e degradação protéica por medida de nitrogênio volátil total [11] e foram realizadas logo após o abate dos animais (tempo zero) e durante os períodos $4^{\circ}, 8^{\circ}$ e $12^{\circ}$ dias de estocagem em geladeira $\left(5\right.$ a $\left.8^{\circ} \mathrm{C}\right)$. As medidas de estabilidade $(\mathrm{pH}$, NVT) foram sempre acompanhadas pela avaliação da carga microbiológica presente ao longo de todo o estudo.

Acompanhou-se também a estabilidade da carne de ema sob congelamento por mieio das medidas de $\mathrm{pH}$ [10] e de oxidação lipídica - TBA [25], além da avaliação da carga microbiológica presente em cada etapa de estudo. Essas avaliações foram realizadas no tempo zero, aos 15 dias de congelamento e a cada 30 dias durante um período de dois meses.
As análises microbiológicas foram realizadas na carne in natura sob refrigeração e congelamento, conforme os Padrões Microbiológicos Sanitários para Alimentos, recomendada pela Agência Nacional de Vigilância Sanitária (Anvisa), de acordo com a Resolução - RDC n ${ }^{\circ} 12$, de 2 de janeiro de 2001, do regulamento da Anvisa aprovado pelo Decreto 3.029 [7]. Assim, foram avaliadas a presença de coliformes totais, coliformes de origem fecal (Escherichia coli) e psicrotróficos.

O cálculo do número mais provável (NMP) de coliformes totais foi realizado com o auxílio da tabela de Hoskins [31]. Avaliou-se a quantidade de coliformes fecais por meio da técnica dos tubos múltiplos [31]. A determinação de aeróbios psicrotróficos foi realizada segundo SILVA; JUNQUEIRA; SILVEIRA [31].

\section{3 - RESULTADOS E DISCUSSÃo}

\section{1 - Análises microbiológicas (refrigeração e congelamento)}

Acompanhou-se a estabilidade da carne de ema armazenada sob refrigeração $\left(5\right.$ a $\left.8^{\circ} \mathrm{C}\right)$ e congelamento $\left(-18^{\circ} \mathrm{C}\right)$, quando foram avaliadas amostras, em triplicata, de cada lote de abate.

No que refere-se a coliformes totais, a grande maioria das amostras sob refrigeração e congelamento (Tabelas 1 e 2) não apresentaram contaminação. As que apresentaram suspeita de contaminação, no teste confirmativo para Escherichia coli, deram resultados negativos. Assim, a avaliação microbiológica mostra que, a totalidade das amostras ao longo do período experimental, foi considerada adequada ao consumo, por atender aos padrões estabelecidos pela legislação vigente para carnes resfriadas ou congeladas in natura de aves [7]. Para essa avaliação, foi considerada a legislação para carne de aves, por não existir ainda uma norma específica para carne de ratitas (ema ou avestruz).

Com a contagem de coliformes totais/fecais é possível acompanhar a carga microbiana inicial e as condições higiênicosanitárias da matéria-prima utilizada, das condições de abate e manipulação pós-abate. Portanto, a qualidade microbiológica conseguida parece justificar as condições higiênico-sanitárias, bastante satisfatórias do trabalho realizado.

ÂNGULO \& ÂNGULO [3], avaliando características de qualidade da carne de avestruz comercializada na cidade de Córdoba (Espanha), relatam que essa fonte alternativa de proteína animal está sendo comercializada de uma forma pouco segura do ponto de vista microbiológico. Isso porque, as amostras de carne de avestruz frescas refrigeradas analisadas, apresentaram contagens de coliformes iguais a $2,7 \times 10^{4}$ a $4,6 \times 10^{7}$, valores acima dos padrões microbiológicos vigentes para carne de aves na legislação espanhola.

Os resultados favoráveis dos testes microbiológicos, encontrados no presente estudo de armazenamento sob refrigeração e congelamento da carne de ema, podem ser atribuídos a uma somatória de efeitos. O manejo adequado 
antes do abate, dieta hídrica dos animais, temperatura e higiene do local de abate e desossa, correta evisceração, manipulação e armazenamento adequados das carnes pós-abate, resultaram em uma satisfatória qualidade higiênico-sanitária do produto final.

TABELA 1 - Análises microbiológicas das amostras de carne de ema armazenadas sob diferentes períodos de refrigeração $\left(5\right.$ a $\left.8^{\circ} \mathrm{C}\right)$

\begin{tabular}{|c|c|c|c|}
\hline & $\begin{array}{c}\text { Coliformes } \\
\text { totais } \\
\text { (NMP/g) }\end{array}$ & $\begin{array}{c}\text { Coliformes } \\
\text { fecais } \\
\text { (NMP/g) }\end{array}$ & $\begin{array}{l}\text { Escherichia coli } \\
\text { (confirmativo) }\end{array}$ \\
\hline \multicolumn{4}{|l|}{ Lote 1} \\
\hline \multicolumn{4}{|c|}{ Armazenamento } \\
\hline 0 dias & 43 & 3 & Negativo \\
\hline 4 dias & 4 & $<3$ & Negativo \\
\hline 8 dias & 3 & $<3$ & Negativo \\
\hline 12 dias & $<3$ & $<3$ & Negativo \\
\hline \multicolumn{4}{|l|}{ Lote 2} \\
\hline \multicolumn{4}{|c|}{ Armazenamento } \\
\hline 0 dias & $<3$ & $<3$ & Negativo \\
\hline 4 dias & $<3$ & $<3$ & Negativo \\
\hline 8 dias & $<3$ & $<3$ & Negativo \\
\hline 12 dias & $<3$ & $<3$ & Negativo \\
\hline \multicolumn{4}{|l|}{ Lote 3} \\
\hline \multicolumn{4}{|c|}{ Armazenamento } \\
\hline 0 dias & 9 & $<3$ & Negativo \\
\hline 4 dias & $<3$ & $<3$ & Negativo \\
\hline 8 dias & $<3$ & $<3$ & Negativo \\
\hline 12 dias & $<3$ & $<3$ & Negativo \\
\hline \multicolumn{4}{|l|}{ Lote 4} \\
\hline \multicolumn{4}{|c|}{ Armazenamento } \\
\hline 0 dias & $<3$ & $<3$ & Negativo \\
\hline 4 dias & $<3$ & $<3$ & Negativo \\
\hline 8 dias & $<3$ & $<3$ & Negativo \\
\hline 12 dias & $<3$ & $<3$ & Negativo \\
\hline
\end{tabular}

TABELA 2 - Análises microbiológicas das amostras de carne de ema armazenadas sob diferentes períodos de congelamento $\left(-18^{\circ} \mathrm{C}\right)$

\begin{tabular}{lccc}
\hline & $\begin{array}{c}\text { Coliformes } \\
\text { totais } \\
\text { (NMP/g) }\end{array}$ & $\begin{array}{c}\text { Coliformes } \\
\text { fecais } \\
\text { (NMP/g) }\end{array}$ & $\begin{array}{c}\text { Escherichia coli } \\
\text { (confirmativo) }\end{array}$ \\
\hline Lote 1 & & & \\
\hline Armazenamento & 43 & $<3$ & Negativo \\
15 dias & 43 & 9 & Negativo \\
30 dias & 9 & $<3$ & Negativo \\
60 dias & & & \\
\hline Lote 2 & & & \\
\hline Armazenamento & $<3$ & $<3$ & Negativo \\
15 dias & $<3$ & $<3$ & Negativo \\
30 dias & $<3$ & $<3$ & Negativo \\
60 dias & & & \\
\hline Lote 3 & & & Negativo \\
\hline Armazenamento & 4 & $<3$ & Negativo \\
15 dias & 4 & $<3$ & Negativo \\
30 dias & $<3$ & $<3$ & Negativo \\
60 dias & & & Negativo \\
\hline Lote 4 & & $<3$ & \\
\hline Armazenamento & $<3$ & $<3$ & \\
15 dias & $<3$ & $<3$ & \\
30 dias & $<3$ & & \\
60 dias & & & \\
\hline
\end{tabular}

\section{2 - Estabilidade de armazenamento sob refrigeração $\left(5\right.$ a $\left.8^{\circ} \mathrm{C}\right)$}

O objetivo foi estimar o tempo de vida útil da carne de ema para o consumo, quando armazenada sob refrigeração, por meio da avaliação de Nitrogênio Volátil Total (NVT), pH e microorganismos psicrotróficos.

Através da quantificação do conteúdo de NVT, determina-se a degradação protéica ocorrida numa carne, pela proliferação bacteriana ou ação enzimática do próprio tecido, com liberação de bases voláteis (trimetilamina-TMA). O conteúdo de TMA não possui correlação aparente com características sensoriais, no entanto, existe uma correlação significativa entre conteúdo de TMA e NVT [11].

Não foi encontrado na literatura trabalho referente a determinações de NVT em carne de ratitas (ema, avestruz, emu).

Na Tabela 3, observa-se que os valores de NVT para a carne de ema sob refrigeração apresentaram um aumento médio em torno de $4 \%$ entre o tempo zero (dia de abate) e o $12^{\circ}$ dia de armazenamento, sendo que o maior aumento aconteceu no lote 4 (9\%). Estes resultados denotam uma evolução insignificante dos valores de NVT para a carne sob refrigeração. Isso significa um relativo equilíbrio entre os resultados de NVT e análises microbiológicas, pelo fato de as amostras não apresentarem desenvolvimento de microorganismos proteolíticos (Tabela 5).

No entanto, BADR [5] relatou que a carne de coelho armazenada sob refrigeração $\left( \pm 4^{\circ} \mathrm{C}\right)$ apresentou um aumento significativo no conteúdo de NVT no período de estocagem (de 29,422 no tempo zero, para 51,153 mg N/100 g amostra no $6^{\circ}$ dia), e foi rejeitada para consumo no $9^{\circ}$ dia, a partir de avaliação sensorial (aparência e odor). Nesse estudo, o autor sugere que a degradação protéica observada foi devido à atividade microbiana.

NAIK et al. [22], para avaliarem a vida de prateleira da carne de búfalo em bife, sob refrigeração $\left(3^{\circ} \mathrm{C}\right)$, utilizaram como um dos indicativos de deterioração da carne, o valor de NVT. Os autores relataram que houve um aumento significativo no conteúdo de NVT no período de armazenamento. Nesse estudo, a partir da análise sensorial (cor e odor), a carne foi rejeitada pelos provadores após duas semanas de refrigeração, quando apresentava valores de NVT em torno de $45 \mathrm{mg}$ de N/100 g amostra.

EGAN; KIRK e SAWYER [11] consideraram o NVT como indicador da deterioração protéica, observando que para carne bovina valores até $16,5 \mathrm{mg} / 100 \mathrm{~g}$ amostra é considerado aceitável, já para peixe fresco os valores menores que 20, aponta uma carne fresca; 30 já indica carne envelhecida e $40 \mathrm{mg} / 100 \mathrm{~g}$ amostra dava como imprópria para consumo. Com base nesse estudo e nos valores médios da Tabela 3 (8,90 - 9,28 mg de N/100 g amostra), o armazenamento sob refrigeração no período de 12 dias, conserva a carne de ema com características apropriadas para consumo. 
TABELA 3 - Valores médios de NVT das amostras de carne de ema armazenadas sob diferentes períodos de refrigeração $\left(5\right.$ a $\left.8^{\circ} \mathrm{C}\right)$

\begin{tabular}{lccccc}
\hline \multirow{2}{*}{$\begin{array}{l}\text { Dias de } \\
\text { armazenamento }\end{array}$} & \multicolumn{5}{c}{ NVT ( $\mathbf{m g}$ de N/100 g de amostra) } \\
\cline { 2 - 6 } & Lote 1 & Lote 2 & Lote 3 & Lote 4 & Média \\
\hline 0 & 9,10 & 9,11 & 8,77 & 8,60 & $8,90( \pm 0,25)^{*}$ \\
4 & 9,19 & 9,27 & 8,83 & 8,66 & $8,99( \pm 0,29)$ \\
8 & 9,26 & 8,93 & 8,86 & 9,23 & $9,07( \pm 0,21)$ \\
12 & 9,42 & 9,24 & 9,05 & 9,40 & $9,28( \pm 0,17)$ \\
\hline *Desvio padrão & & & & &
\end{tabular}

Na Tabela 4, estão apresentados os valores de $\mathrm{pH}$ da carne de ema armazenada sob refrigeração, na qual observa-se que o $\mathrm{pH}$ manteve-se praticamente estável, em torno de 5,8, com pequenas oscilações durante todo o período de estocagem (12 dias).

Uma característica especial da carne de avestruz é dada por possuir um $\mathrm{pH}$ final relativamente alto $( \pm 6,0)$, quando medido após $24 \mathrm{~h}$ do abate. A cor vermelha intensa da carne do avestruz pode ser explicada pelo alto $\mathrm{pH}$ final. Aspectos positivos e negativos advêm deste fato. O positivo é que geralmente a cor vermelha intensa agrada ao consumidor, por outro lado, os aspectos negativos dizem respeito ao pequeno tempo de conservação para a carne resfriada, pois, com um pH em torno de 6,0, a susceptibilidade é maior para a ação de bactérias [8].

A redução das reservas de glicogênio nos músculos, em função do estresse ante mortem, é a principal causa do elevado $\mathrm{pH}$ final da carne das espécies de ratitas. Para que a carne de avestruz, por exemplo, apresente uma boa característica de maciez, o pH deve ser inferior a 5,8 e não deve ultrapassar 6,2, pois a carne pode se tornar extremamente escura, firme e seca (DFD) [29].

OTEMBRA; DIKEMAN e BOYLE [23], avaliando a vida de prateleira sob refrigeração $\left(0^{\circ} \mathrm{C}\right)$ da carne de avestruz previamente congelada $\left(-40^{\circ} \mathrm{C}\right)$ e embalada a vácuo, relataram que a carne de avestruz moída apresentou uma queda do $\mathrm{pH}$ de 6,4 ( $3^{\circ}$ dia refrigeração) para 5,7 durante o período de armazenamento ( 28 dias), e que isso pode ter ocorrido devido à presença de ácido lático produzidos pelas bactérias láticas.

AZNAR et al. [4], avaliando parâmetros de qualidade de três categorias (I, II, III) de carne de avestruz embaladas a vácuo e procedentes de estabelecimentos comerciais, apresentou diferenças significativas nos valores de $\mathrm{pH}: 5,93$, 5,88 e 6,04, para os músculos Iliofibularis (I), Gastrocnemius (II) e região metatarsiana (III), respectivamente. No trabalho de LANZA et al. [16] os valores de $\mathrm{pH}$ medidos diretamente no músculo da carcaça de avestruz, 24 h postmortem, apresentaram diferenças significativas entre $\mathrm{o}$ m. gastrocnemius $(5,98)$ e o $m$. iliofibularis $(6,13)$.

No estudo de acompanhamento da queda do $\mathrm{pH}$ postmortem (0 a $24 \mathrm{~h}$ ), em diferentes músculos de avestruz abatidas em frigorífico comercial, SALES \& MELLETT [30] relataram que os valores do $\mathrm{pH}$ variaram de 5,84 a 6,13 entre os diferentes músculos, e que esses altos valores de pH final, após abate ( $24 \mathrm{~h}$ ), sugerem que a carne de avestruz possa ser classificada como uma carne intermediária entre "normal" ( $\mathrm{pH}<5,8)$ e DFD $(\mathrm{pH}>6,2)$. Nesse estudo, apresentaram $\mathrm{pH}$ de 5,94 para o $\mathrm{m}$. Iliotibialis lateralis e 6,13 para $m$. Iliofibularis, entre outros estudados.

POLLOK et al. [26] recomendam que bifes de carne de avestruz embalados a vácuo não permaneçam armazenados sob refrigeração por mais de 14 dias, pois pode comprometer a qualidade da carne. Já OTEMBRA; DIKEMAN; BOYLE [23] relataram que a carne de avestruz embalada a vácuo e estocada sob refrigeração apresenta-se em condições de consumo até o $10^{\circ}$ dia de estocagem.

TABELA 4 - Valores de $\mathrm{pH}$ das amostras de carne de ema armazenadas sob diferentes períodos de refrigeração $\left(5\right.$ a $\left.8^{\circ} \mathrm{C}\right)$

\begin{tabular}{lcccc}
\hline \multirow{2}{*}{$\begin{array}{l}\text { Dias de } \\
\text { armazenamento }\end{array}$} & \multicolumn{4}{c}{ LH } \\
\cline { 2 - 5 } & Lote 1 & Lote 2 & Lote 3 & Lote 4 \\
\hline 0 & $5,70( \pm 0,71)^{\star}$ & $5,75( \pm 0,04)$ & $5,57( \pm 0,01)$ & $5,98( \pm 0,04)$ \\
4 & $5,64( \pm 0,01)$ & $5,85( \pm 0,04)$ & $5,85( \pm 0,01)$ & $5,84( \pm 0,02)$ \\
8 & $6,10( \pm 0,14)$ & $5,58( \pm 0,01)$ & $5,88( \pm 0,01)$ & $5,94( \pm 0,01)$ \\
12 & $5,86( \pm 0,06)$ & $5,83( \pm 0,01)$ & $5,97( \pm 0,01)$ & $5,89( \pm 0,01)$ \\
\hline${ }^{*}$ Desvio padrão & & & &
\end{tabular}

Observou-se, na Tabela 5, que praticamente não houve ocorrência de microorganismos psicrotróficos nas amostras de carne de ema refrigeradas por um período de 12 dias. Pode-se atribuir estes resultados favoráveis à qualidade da matéria-prima devidamente manipulada, processada e armazenada em temperaturas adequadas, confirmando o que foi relatado por FORSYTHE [13].

OTEMBRA; DIKEMAN; BOYLE [25] avaliaram a vida de prateleira da carne de avestruz (Gastrocnemius internus - bife e moído) armazenada sob refrigeração a $0^{\circ} \mathrm{C}$ (período 28 dias), que foi previamente embalada a vácuo e congelada a $-40^{\circ} \mathrm{C}$ durante cinco dias. No citado trabalho, a contagem de psicrotróficos para carne moída de avestruz até o $3^{\circ}$ dia de armazenamento manteve-se constante, ocorrendo depois um desenvolvimento significativo desses microorganismos até 21 dias de estocagem (contagem de $1,7 \times 10^{7} \mathrm{UFC} / \mathrm{cm}^{2}$, no final do período de refrigeração).

FORREST et al. [12] relataram que em virtude de um pH mais alto da carne, a deterioração é mais fácil de ocorrer pelo desenvolvimento de bactérias proteolíticas. Segundo FRANCO \& LANDGRAF [14], a quantidade e tipos de microorganismos que se desenvolvem na carne dependerão das condições de abate, estresse do animal, evisceração correta, entre outros. FORSYTHE [13] também observou que a vida de prateleira depende da flora microbiana inicial do produto, ou seja, quanto maior a carga inicial, menor a vida de prateleira devido ao aumento da atividade microbiana, observações que não foram detectadas no presente estudo.

Em função do que foi exposto, podemos inferir que a carne de ema (Rhea americana) armazenada sob refrigeração apresenta estabilidade em condições de consumo até 12 dias de armazenamento. 
Os resultados favoráveis obtidos para a carne refrigerada indicam que o procedimento tecnológico aqui adotado (dieta hídrica, abate, esfola, evisceração, manipulação das amostras) pode servir de orientação para o abate de emas em futuros abatedouros.

TABELA 5 - Contagem de microrganismos psicrotróficos das amostras de carne de ema armazenada sob diferentes períodos de refrigeração $\left(5\right.$ a $\left.8^{\circ} \mathrm{C}\right)$

\begin{tabular}{lcccc}
\hline Dias de & \multicolumn{4}{c}{ Psicrotróficos (UFC/g) } \\
\cline { 2 - 5 } armazenamento & Lote 1 & Lote 2 & Lote 3 & Lote 4 \\
\hline 0 & $<30$ & $<30$ & $<30$ & $<30$ \\
4 & $<30$ & $<30$ & $<30$ & $<30$ \\
8 & $<30$ & $<30$ & $<30$ & $<30$ \\
12 & $8,0 \times 10^{3}$ & $<30$ & $<30$ & $<30$ \\
\hline
\end{tabular}

\section{3 - Estabilidade de armazenamento sob congelamento $\left(-18^{\circ} \mathrm{C}\right)$}

A vida de prateleira sob congelamento foi avaliada pelo acompanhamento de $\mathrm{pH}$, TBA e análises microbiológicas das amostras de carne de ema, durante o período de 60 dias.

As medidas de pH estão apresentados na Tabela 6 , indicando valores entre 5,43 a 5,98, sendo possível observar que não houve alterações significativas ao longo do período de congelamento. Não encontrou-se, na literatura, trabalhos referentes a estudo de estabilidade sob congelamento de carne de ratitas (ema, avestruz, emu).

LEE; CHOI e YOON [17], estudando a vida de prateleira da carne suína estocada a $0^{\circ} \mathrm{C}$, observaram não haver alterações significativas do $\mathrm{pH}$ das amostras, mantendo-se na faixa de 5,7-5,9 até o final do período estudado (14 dias).

TABELA 6 - Valores de pH das amostras de carne de ema armazenadas sob diferentes períodos de congelamento $\left(-18^{\circ} \mathrm{C}\right)$

\begin{tabular}{lcccc}
\hline \multirow{2}{*}{$\begin{array}{l}\text { Dias de } \\
\text { armazenamento }\end{array}$} & \multicolumn{4}{c}{ pH } \\
\cline { 2 - 5 } & Lote 1 & Lote 2 & Lote 3 & Lote 4 \\
\hline 0 & $5,70( \pm 0,71)^{\star}$ & $5,75( \pm 0,04)$ & $5,57( \pm 0,01)$ & $5,98( \pm 0,04)$ \\
15 & $5,42( \pm 0,01)$ & $5,77( \pm 0,01)$ & $5,66( \pm 0,08)$ & $5,81( \pm 0,02)$ \\
30 & $5,52( \pm 0,02)$ & $5,62( \pm 0,03)$ & $5,64( \pm 0,11)$ & $5,75( \pm 0,01)$ \\
60 & $5,63( \pm 0,01)$ & $5,52( \pm 0,06)$ & $5,68( \pm 0,01)$ & $5,77( \pm 0,02)$ \\
\hline *Desvio padrão & & & &
\end{tabular}

Na Tabela 7, observa-se que os valores de TBA da carne congelada sofreram aumento considerável, entre 0 e 15 dias de estocagem, para os lotes 1 e 2 (109\% e $131 \%$, respectivamente), sendo que os lotes 3 e 4 apresentaram variações menores ( $17 \%$ e $23 \%$ ). Já para o período de 15 a 30 dias de armazenamento, a situação foi inversa, uma vez que os lotes 1 e 2 tiveram um aumento menor no $n^{\circ}$ TBA ( $61 \%$ e 54\%), em relação a uma variação relativamente alta que ocorreu nos lotes 3 e 4, que apresentaram um aumento de $226 \%$ e $283 \%$, respectivamente. Observando-se as alterações de número de TBA ocorridas no período de 0 a 60 dias, verifica-se que ocorreu um aumento em todos os lotes estudados.
Relacionando o teor médio de lipídio das amostras de cada lote $(2,06 \%$ - lote $1 ; 1,39 \%-2 ; 1,33 \%-3 ; 1,33 \%-4)$ com o $\mathrm{n}^{\mathrm{o}}$ de TBA correspondente, pode-se observar uma relativa coerência entre os resultados. O lote 1 apresentou o maior teor de lipídio e, conseqüentemente, a maior variação no $\mathrm{n}^{\circ}$ de TBA; o mesmo ocorrendo com o lote 2 , que mostrou uma oxidação lipídica mais acentuada que os lotes 3 e 4, os quais apresentaram um comportamento muito semelhante, já que possuem o mesmo conteúdo lipídico.

Por esses resultados, admite-se que apesar da baixa concentração de lipídios existente na carne de ema, parece ocorrer uma susceptibilidade alta à oxidação lipídica; o que pode estar relacionado ao perfil qualitativo e quantitativo dos ácidos graxos existentes na carne. Acreditamos que maiores esclarecimentos serão obtidos com o estudo do perfil dos ácidos graxos da carne de ema.

Os substratos das reações de oxidação lipídica são, principalmente, os ácidos graxos insaturados. É o grau de instauração que mais influi na velocidade de oxidação, sendo que os ácidos graxos poliinsaturados se oxidam até em alimentos congelados [10].

MORCUENDE et al. [20], avaliando a estabilidade oxidativa de diferentes músculos da carcaça suína, armazenados sob refrigeração $\left(4^{\circ} \mathrm{C}\right)$ durante 10 dias, relataram que os valores de TBA tiveram uma tendência de aumento no período de estocagem ( $m$. Masseter - 0,39 a 1,13 mg SRTBA/kg amostra; $m$. Longissimus dorsi - 0,36 a 0,65 mg SRATB/kg amostra; $m$. Serratus ventralis - 0,37 a 0,60 mg SRATB/kg amostra).

No trabalho de PIKUL; LESZCZYNSKI e KUMMEROW [24], observam-se valores de TBA para músculo do peito e da coxa de frango de 3,29 e 7,79 mg de SRATB/1000 g, respectivamente; sendo que a coxa apresentou $n^{\circ}$ TBA duas vezes maior que o peito, principalmente, por possuir duas vezes mais gordura.

BADR [5], avaliando a vida de prateleira da carne de coelho, sob refrigeração $\left( \pm 4^{\circ} \mathrm{C}\right)$, relatou que o número de TBA aumentou significativamente durante o período de estocagem $(0,287$ para 0,697 mg de malonaldeído/kg amostra), sendo que no $9^{\circ}$ dia a carne foi rejeitada para consumo. O autor também sugere que este fato está relacionado com o alto teor de ácidos graxos poliinsaturados presentes na carne de coelho.

Geralmente, a carne moída apresenta maiores valores de TBA em relação a pedaços inteiros [32]. Provavelmente, essa ocorrência esteja ligada ao fato de que a ruptura das membranas celulares pela trituração libera fosfolipídios, acelerando a oxidação lipídica dos tecidos. Os fosfolipídios, que são constituintes das membranas celulares e intracelulares, são muito susceptíveis à oxidação por serem ricos em ácidos graxos insaturados. Em função disso, o tecido muscular é mais sensível a oxidação de lipídios do que o tecido adiposo, rico em triglicerídeos saturados. Assim, admite-se que a carne de aves é mais oxidável, pois seus constituintes fosfolipídicos são mais ricos em ácidos graxos insaturados [9]. 
A estabilidade lipídica em carnes e produtos cárneos é influenciada por muitos fatores, incluindo espécie, dieta, estado nutricional e idade do animal antes do abate, tipo de músculo (localização anatômica), manipulação da amostra (processamento, crua, cozida), além do método utilizado para as análises (MELTON [19]; MORRISSEY et al. [21]; RHEE; ANDERSON; SAMS [28]).

TABELA 7 - Número de TBA das amostras de carne de ema armazenadas sob diferentes períodos de congelamento $\left(-18^{\circ} \mathrm{C}\right)$

\begin{tabular}{lccccc}
\hline \multirow{2}{*}{$\begin{array}{l}\text { Dias de } \\
\text { armazenamento }\end{array}$} & \multicolumn{5}{c}{ TBA (mg de SRTBA/1000 g de amostra) } \\
\cline { 2 - 6 } & Lote 1 & Lote 2 & Lote 3 & Lote 4 & Média \\
\hline 0 & 0,821 & 0,493 & 0,461 & 0,447 & $0,556( \pm 0,18)^{*}$ \\
15 & 1,717 & 1,137 & 0,540 & 0,553 & $0,987( \pm 0,55)$ \\
30 & 2,767 & 1,750 & 1,223 & 1,564 & $1,826( \pm 0,63)$ \\
60 & 2,552 & 1,933 & 1,803 & 2,292 & $2,145( \pm 0,39)$ \\
\hline *Desvio padrão & & & & &
\end{tabular}

A presença de microorganismos psicrotróficos, nos alimentos, também está relacionada diretamente às condições de higiene do processamento. Esses microorganismos têm a capacidade de crescimento a temperaturas próximas do congelamento, e multiplicam-se bem em alimentos refrigerados, sendo assim os principais agentes de deterioração das carnes refrigeradas e congeladas [14]. O congelamento rápido e o descongelamento adequado podem ser fatores importantes no controle dos microorganismos.

Na Tabela 8, observa-se a contagem de psicrotróficos na carne de ema congelada $\left(-18^{\circ} \mathrm{C}\right)$, indicando que não houve deterioração da carne em função do desenvolvimento desses microorganismos, uma vez que não foi detectada sua presença nas amostras analisadas.

No trabalho de ABURUWAIDA et al. [2], no qual avaliaram a qualidade microbiológica de carcaças de frangos congeladas, os dados obtidos mostraram contagem inicial relativamente baixa para psicrotróficos em todas as amostras analisadas. O período de congelamento não causou mudanças substanciais na contagem de psicrotróficos nas carcaças armazenadas a $-12^{\circ} \mathrm{C}$. Já o número de bactérias viáveis diminuiu significativamente em carcaças estocadas a $-18^{\circ} \mathrm{C}$.

No entanto, ABURUWAIDA et al. [1], estudando a incidência de microorganismos que influenciam a vida de prateleira de carne de frango congelada, observaram que a contagem de psicrotróficos aumentou de log 3,4 para log $7,2 \mathrm{UFC} / \mathrm{g}$ depois de três meses de estocagem a $-5^{\circ} \mathrm{C}$, e foi acompanhado de mudanças sensoriais e organolépticas da carne, além do aumento do nitrogênio volátil total (NVT).

TABELA 8 - Contagem de microrganismos psicrotróficos das amostras de carne de ema armazenadas sob diferentes períodos de congelamento $\left(-18^{\circ} \mathrm{C}\right)$

\begin{tabular}{lcccc}
\hline \multirow{2}{*}{$\begin{array}{l}\text { Dias de } \\
\text { armazenamento }\end{array}$} & \multicolumn{4}{c}{ Psicrotróficos (UFC/g) } \\
\cline { 2 - 5 } & Lote 1 & Lote 2 & Lote 3 & Lote 4 \\
\hline 15 & $<30$ & $<30$ & $<30$ & $<30$ \\
30 & $<30$ & $<30$ & $<30$ & $<30$ \\
60 & $<30$ & $<30$ & $<30$ & $<30$ \\
\hline
\end{tabular}

PRANDL et al. [29] sugeriram que para se ter uma carne congelada com qualidade adequada, um nível apropriado de higiene nas operações de abate e separação dos segmentos de interesse (carne, vísceras) são considerados requisitos imprescindíveis. Assim, os resultados favoráveis obtidos para a carne de ema (Rhea americana) congelada, como já foi mencionado no estudo de refrigeração, indicam que o procedimento tecnológico realizado, no presente estudo, foi apropriado para a conservação dessa carne em condições de consumo por um período de 2 meses.

\section{4 - CONCLUSÕES}

As condições de armazenamento foram apropriadas para a conservação da carne de ema, em condições de consumo, por um período de 12 dias sob refrigeração $\left(5\right.$ a $\left.8^{\circ} \mathrm{C}\right)$ e 60 dias sob congelamento $\left(-18^{\circ} \mathrm{C}\right)$.

Os resultados favoráveis com relação às análises microbiológicas (coliformes totais/fecais e psicrotróficos) indicam que os processamentos tecnológicos adotados, em nossos estudos, poderão ser utilizados comercialmente para a obtenção de uma carne com qualidade higiênico sanitária.

Como a literatura científica é muito escassa nessa área, observa-se a necessidade de outros estudos para melhor caracterização da carne de ema, sob os aspectos de vida de prateleira, qualidade da carne e avaliação do processo de abate.

\section{5 - REFERÊNCIAS BIBLIOGRÁFICAS}

[1] ABURUWAIDA, A.S. et al. Incidence of microorganisms affecting shelf-life, quality and safety of locally-produced frozen broiler chickens in Kuwait. Arab Gulf Journal of Scientific Research, v. 14, n. 3, p. 609-628, 1996a.

[2] ABURUWAIDA, A.S. et al. Microbiological shelf-life and quality of frozen broiler chickens stored Ander simulated market temperatures. Fleischwirtschaft, v. 76, n. 8, p. 827-830, 1996b.

[3] ANGULO, R.; ANGULO M. Comer carne de avestruz: es una alternativa segura? Alimentaria, v. 38, n. 327, p. 51-54, nov. 2001.

[4] AZNAR, A. et al. Evaluacion de parâmetros de calidad de três categorias comerciales de carne de avestruz. Alimentaria, v. 37, n. 316, p. 65-67, Oct. 2000.

[5] BADR, H.M. Use of irradiation to control foodborne pathogens and extend the refrigerated market life of rabbit meat. Meat Science, v. 67, n. 4, p. 541-548, Aug. 2004.

[6] BLAKE, J.P. Perspectivas na produção comercial de espécies avícolas de grande porte (Avestruzes, Emu e Rhea). In: Conferência Apinco de Ciência e Tecnologia Avícolas, 1996, Curitiba. Anais... Curitiba: Facta, 1996, p. 1-6.

[7] BRASIL. Ministério da Saúde. Anvisa, Resolução - RDC $\mathrm{n}^{\mathrm{o}} 12$, de 2 de janeiro de 2001. Aprova o regulamento técnico sobre padrões microbiológicos para alimentos. Diário Oficial da União, Brasília (DF), 10 jan. 2001, Seção 1, p. 45-54.

[8] CARRER, C.C.; KORNFELD, M.E. Importância econômica, mercado e produtos. In: CARRER, C.C., KORNFELD, M.E. (Ed). A criação de avestruzes no Brasil. 
Pirassununga: Brasil Ostrich, 1999, p. 25-51.

[9] CHEFTEL, J.C.; CHEFTEL, H. Oxidacion de lipidios. In: CHEFTEL, J.C.; CHEFTEL, H. (Ed.). Introdución a la bioquímica y tecnología de los alimentos. Zaragoza: Acribia, 1980, p. 265-290, v. 1.

[10] DUTSON, T.R. The measurement of pH in muscle and its importance to meat quality. In: RECIPROCAL MEAT CONFERENCE, 36, 1983. Proceedings... [S.1.: s.n.], 1983, p. 92-97.

[ 11 ] EGAN, H.; KIRK, R.S.; SAWYER, R.S. Pearson's chemical analysis of foods. $8^{\text {th }}$ ed. Edinburgh: Churchill Livingstone, 1981, $591 \mathrm{p}$.

[12] FORREST, C.J. et al. Valor nutritivo. In: FORREST, C.J.; ABERLE, E.D.; HEDRICK, H.B. (Ed.). Fundamentos de la ciência de la carne. Zaragoza: Acribia, 1979, p. 265-274.

[13] FORSYTHE, S.J. Microbiologia da segurança alimentar. Porto Alegre: Artmed, 2002, p. 109-121.

[14] FRANCO, B.D.G.M.; LANDGRAF, M. Microbiologia dos alimentos. São Paulo: Atheneu, 2001, p. 27-31, p. 125-134.

[15] GIANNONI, M.L. Criação de avestruzes e emas. São José do Rio Preto: [s.n.], 2001, 55 p., Apostila.

[16] LANZA, M.; et al. Citrus pulp as an ingredient in ostrich diet: effects on meat quality. Meat Science, v. 68 , n. 2, p. 269-275, Oct. 2004.

[17] LEE, K.T.; CHOI W.S.; YOON C.S. Effects of micro-perforated film on the quality and shelf life improvements of pork loins during chilled storage. Meat Science, v. 66, n. 1, p. 77-82, Jan. 2004.

[18] LUENGO, M.C. et al. Análisis nutricional y evaluación sensorial de la carne de choique. Seminario - Taller: Conservación y Manejo del Choique en la Patagonia, 1998, Bariloche. Anais... Bariloche: INTA, [2000], p.33-34.

[19] MELTON, S.L. Methodology for following lipid oxidation in muscle foods. Journal Food Technology, v. 37, n. 7, p. 105-111, 1983.

[20] MORCUENDE, D. et al. Oxidative and lipolytic deteriotation of different muscles from free-range reared Iberian pigs under refrigerated storage. Meat Science, v. 65 , n. 4, p. 1.157-1.164, Dec. 2003.

[21] MORRISSEY, P.A. et al. Lipid stability in meat and meat products. Meat Science, v. 49, n. 1, p. S73-S86, 1998, Supplement.

[22] NAIK, G.N. et al. Influence of low dose irradiation on the quality of fresh buffalo meat stored at $0-3^{\circ} \mathrm{C}$. Meat Science, v. 38, n. 2, p. 307-313, 1994.
[23] OTEMBRA, M.M.; DIKEMAN, M.E.; BOYLE, E.A.E. Refrigerated shelf life of vaccum-packaged, previously frozen ostrich meat. Meat Science, v. 52, n. 3, p. 279283, July 1999.

[24] PIKUL, J.; LESZCZYNSKI, D.E.; KUMMEROW, F.A. Elimination of sample autoxidation by butylated hydroxytoluene additions before thiobarbituric acid assay for malonaldehyde in fat from chicken meat. Journal Agriculture Food Chemical, v. 31, n. 6, p. 1.338-1.342, 1983.

[25] PIKUL, J.; LESZCZYNSKI, D.E.; KUMMEROW, F.A. Evaluation of three modified TBA methods for measuring lipid oxidation in chicken meat. Journal Agriculture Food Chemical, v. 37, n. 5, p. 1.3091.313, Sep.-Oct. 1989.

[26] POLLOK, K.D. et al. Quality of ostrich steaks as affected by vacuum-package storage, retail display and differences in animal feeding regimen. American Ostrich, p. 46-52, Apr. 1997.

[27] PRÄNDL, O. et al. Tecnologia e hygiene de la carne. Zaragoza: Acribia, 1994, 854 p.

[28] RHEE, K.S., ANDERSON, L.M., SAMS, A.R. Lipid oxidation potential of beef, chicken and pork. Journal Food Science, v. 61, n. 8-12, Jan.-Feb. 1996.

[29] SALES, J.; HAYES J.P. Proximate, amino acid and mineral composition of ostrich meat. Food Chemistry, v. 56, n. 2, p. 167-170, 1996.

[30] SALES, J.; MELlETT, F.D. Post-mortem pH decline in different ostrich muscles. Meat Science, v. 42 , n. 2, p. 235-238, 1996.

[31] SILVA, N.; JUNQUEIRA, V.C.A.; SILVEIRA, N.F.A. Manual de métodos de análise microbiológica de alimentos. $2^{\mathrm{a}}$ ed. São Paulo: Varela, 2001, 317 p.

[32] ZIAUDDIN, K.S. et al. Effect of freezing, thawing and fronzen storage on physico-chemical and sensory characteristics of buffalo meat. Meat Science, v. 35, n. 3, p. 331-340, 1993.

\section{6 - AGRADECIMENTOS}

Ao Parque Ecológico Dr. Antônio T. Viana, de São Carlos, pela doação dos animais; ao Ibama, por permitir a realização da pesquisa; ao Pólo Regional de Desenvolvimento Tecnológico dos Agronegócios (Apta) - Centro Norte de São José do Rio Preto, por ceder a área necessária à realização do projeto; à Empresa Purina, pelo fornecimento da ração experimental e à Fundenesp, pelo financiamento de parte da pesquisa. 